Volume : 7

Nomor : 2

Bulan : Mei

Tahun : 2021 URL: jurnal.ideaspublishing.co.id

\title{
Faktor Diferensiasi Sekolah di Indonesia
}

Pandu Adi Cakranegara

Fakultas Bisnis, Universitas Presiden

Pos-el: pandu.cakranegara@ president.ac.id

DOI: $10.32884 /$ ideas.v7i2.335

\begin{abstract}
Abstrak
Diferensiasi sekolah di Indonesia yaitu sekolah swasta dan sekolah negeri milik pemerintah. Perbedaan lainnya yaitu sekolah milik yayasan yang berlatar belakang agama atau tanpa latar belakang agama. Tujuan penelitian ini adalah menemukan faktor diferensiasi sekolah di Indonesia. Metode penelitian yang digunakan yaitu deskriptif analitik. Berdasarkan hasil penelitian, ditemukan sepuluh diferensiasi sekolah di Indonesia, yaitu afiliasi, bahasa yang digunakan, latar belakang budaya, kurikulum, waktu belajar di sekolah, nilai etika, jalur ke perguruan tinggi, fasilitas, dan harga.
\end{abstract}

\section{Kata Kunci}

Diferensiasi sekolah, sekolah swasta, sekolah negeri

\begin{abstract}
School differentiation in Indonesia is private schools and government-owned schools. Another difference is that schools belong to foundations with religious or religious backgrounds. The purpose of this study is to find the differentiation factors of schools in Indonesia. The research method used is descriptive analytic. Based on the research results, it was found ten differences in schools in Indonesia, namely provision, language used, cultural background, curriculum, study time at school, ethical values, pathways to tertiary institutions, facilities, and prices.
\end{abstract}

Keywords

Differentiation of schools, private schools, public schools

\section{Pendahuluan}

Diferensiasi sekolah di Indonesia yaitu sekolah swasta dan sekolah negeri milik pemerintah. Perbedaan lainnya yaitu sekolah milik yayasan yang berlatar belakang agama atau tanpa latar belakang agama.

Banyaknya sekolah yang tersedia di masyarakat Indonesia saat ini baik negeri maupun swasta menjadi pilihan bagi orang tua yang akan menyekolahkan anakanaknya. Orang tua umumnya memilih sekolah yang berkualitas dalam pandangan keyakinan mereka. Hal ini sesuai dengan penelitian Andini \& Khasanah (2010) yang menyatakan bahwa faktor kualitas merupakan determinan utama orang tua dalam menentukan sekolah anak.

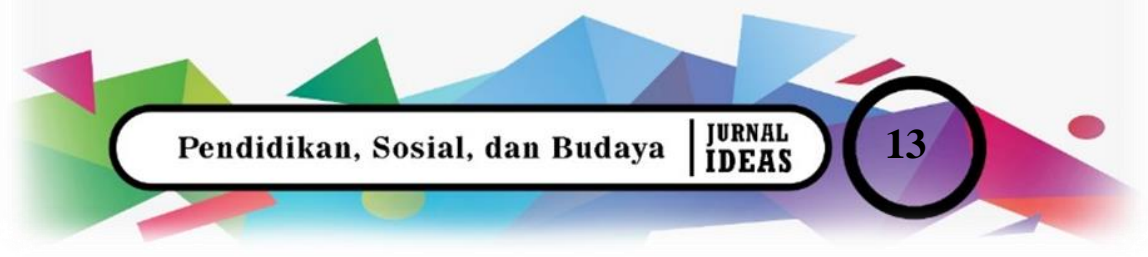


Kualitas sekolah sering dikaitkan dengan harga. Harga yang harus dibayar oleh orang tua tergantung pada harga yang diterbitkan oleh sekolah. Sekolah swasta seringkali lebih mahal tetapi boleh jadi banyak peminat karena kualitas yang ditonjolkan. Sekolah negeri umumnya menerbitkan harga yang lebih murah dan mereka dipilih bukan karena harganya tetapi kualitasnya. Oleh karena itu, sekolah negeri walaupun gratis memungkinkan kesulitan untuk mencari siswa karena kualitas yang masih rendah. Pertanyaannya adalah, mengapa sekolah negeri seperti kekurangan dana untuk menjadikan sekolahnya berkualitas?

Idris (2010) menyatakan bahwa meskipun pemerintah memiliki banyak dana pendidikan dari Anggaran Pendapatan dan Belanja Negara (APBN), tetapi hal tersebut masih belum cukup. Ada beberapa faktor yang menyebabkan anggaran pendidikan ini tidak mencukupi. Pertama, banyaknya sekolah yang menjadi tanggung jawab pemerintah. Kedua, pembangunan Indonesia yang tidak merata, yang berdampak pada kawasan menjadi mahal. Contohnya, membangun sekolah di Papua akan jauh lebih mahal daripada membangun gedung sekolah dengan ukuran yang sama di Jawa. Ketiga, berhubungan dengan kondisi geografis Indonesia. Kondisi geografis Indonesia yang demikian memengaruhi banyak hal, baik dalam penyediaan tenaga guru maupun penyediaan fasilitas sekolah.

Togatorop (2017) meneliti pengaruh signifikan antara biaya pendidikan dan kualitas sekolah di tingkat sekolah menengah swasta. Sampel peneliti menunjukkan bahwa mutu sekolah menengah yang diteliti lugas dengan mutu. Dalam bahasa bisnis digunakan istilah ada uang ada barang. Di satu sisi, hal ini sangat disayangkan karena mekanisme pasar terjadi dalam sistem pendidikan. Namun, di sisi lain, hal ini merupakan konsekuensi logis dari keterbatasan pemerintah dalam menyediakan fasilitas pendidikan.

Berdasarkan permasalahan yang mengemuka tentang perbedaan sekolah di Indonesia, maka peneliti melakukan penelitian untuk menemukan perbedaan tersebut. Peneliti mencoba menjembatani dengan melakukan upaya menemukan diferensiasi sekolah yang ada di Indonesia berdasarkan tiga segmen. 


\section{Volume : 7 \\ Nomor : 2 \\ Bulan : Mei \\ E-ISSH: 2656-940X \\ P-ISSH:2442-367X (D) \\ Tahun : 2021 URL: jurnal.ideaspublishing.co.id}

\section{Metode}

Penelitian ini merupakan penelitian deskriptif analitik. Tujuannya untuk menemukan faktor diferensiasi sekolah di Indonesia. Teknik pengumpulan data menggunakan studi pustaka. Teknik ini digunakan untuk mendapatkan pengukuran terkini sehingga dapat ditemukan faktor diferensiasi sekolah di Indonesia.

Data yang digunakan dari penelitian ini adalah data sekunder, yaitu data dari pihak sekolah itu sendiri yang diperoleh dari website resmi sekolah atau brosur. Informasi lainnya adalah data yang diperoleh dari Kementerian Pendidikan dan Kebudayaan Republik Indonesia. Data tambahan diperoleh dengan melakukan pencarian di internet. Setelah data diperoleh, kemudian dianalisis untuk ditemukan faktor diferensiasinya.

\section{Hasil dan Pembahasan}

\section{Hasil}

Studi ini mengategorikan sekolah ke dalam segmen A, B, dan C. Segmen A memiliki biaya pendidikan tertinggi. Sebaliknya, segmen B memiliki potongan tengah-atas, sedangkan segmen $\mathrm{C}$ memiliki segmen terbawah, yaitu murah atau hampir gratis. Yang cenderung masuk sekolah dengan segmen $\mathrm{C}$ adalah sekolah negeri atau sekolah yang didirikan oleh lembaga keagamaan untuk membantu masyarakat di daerah kurang mampu (Bui dkk., 2020).

Berdasarkan data yang dikumpulkan, terdapat sepuluh faktor diferensiasi pada sekolah di Indonesia. Sepuluh faktor diferensiasi tersebut tersebar di tiga segmen sekolah yang dapat dilihat dalam bentuk tabel 1 berikut ini.

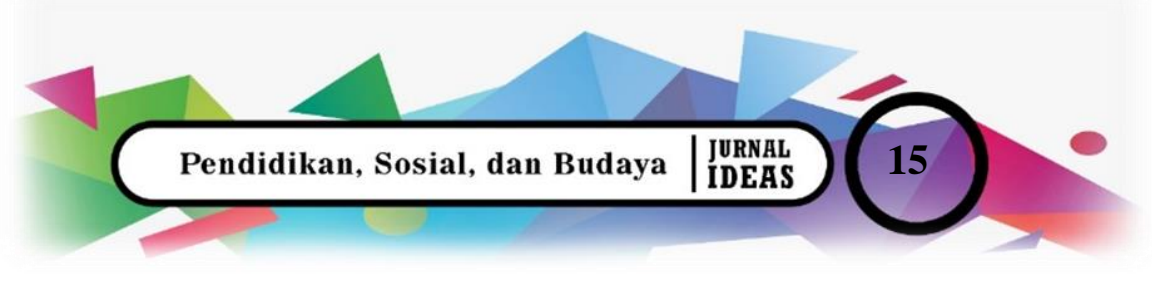


E-ISSH: 2656-940X
P-ISSH: 2442-36TK
URL: jurnal.ideaspublishing.co.id

Volume : 7

Nomor : 2

Bulan : Mei

Tahun : 2021

Tabel 1

Diferensiasi yang Digunakan oleh Sekolah di Indonesia

\begin{tabular}{|c|c|c|c|}
\hline Nilai Diferensiasi & $\mathbf{A}$ & B & $\mathbf{C}$ \\
\hline Kepemilikan & Swasta nasional & Swasta lokal & Publik \\
\hline Afiliasi & $\begin{array}{l}\text { Yayasan yang didirikan oleh } \\
\text { perusahaan }\end{array}$ & Yayasan mandiri & Pemerintah \\
\hline Bahasa yang digunakan & Bahasa asing & Bahasa Inggris & Indonesia \\
\hline Latar belakang budaya & Multikultural & Spesifik negara tertentu & Indonesia \\
\hline Kurikulum & Internasional & $\begin{array}{l}\text { Spesifik salah satu jenis } \\
\text { kurikulum }\end{array}$ & Publik \\
\hline $\begin{array}{l}\text { Waktu belajar di } \\
\text { sekolah }\end{array}$ & Sekolah berasrama & Full day school & $\begin{array}{l}\text { Sekolah } \\
\text { pulang } \\
\text { setiap hari }\end{array}$ \\
\hline Nilai etika & $\begin{array}{l}\text { Berdasarkan nilai-nilai agama } \\
\text { tertentu }\end{array}$ & $\begin{array}{l}\text { Berdasarkan nilai-nilai } \\
\text { tertentu yang tidak selalu } \\
\text { berdasar nilai agama }\end{array}$ & Publik \\
\hline $\begin{array}{lll}\text { Jalur ke perguruan } \\
\text { tinggi }\end{array}$ & Multijalur & Jalur yang spesifik & Umum \\
\hline Fasilitas & Lengkap & Tersedia & Dasar \\
\hline Harga & Tinggi & Tinggi ke medium & $\begin{array}{l}\text { Hampir } \\
\text { gratis }\end{array}$ \\
\hline
\end{tabular}

Sumber: Berbagai Sumber, Penulis, 2020

Secara umum, berdasarkan penelitian ini, sekolah segmen C merupakan sekolah negeri yang dibiayai oleh negara sehingga biayanya murah atau gratis. Namun, karena keterbatasan anggaran, akan ada sekolah negeri favorit pasar dengan fasilitas lebih lengkap dan kinerja lebih tinggi dibandingkan sekolah negeri lain yang tidak mendapat dukungan dana tambahan dari orang tua siswa (Kornbluh, 2019).

Selanjutnya, tabel diferensiasi digunakan untuk menganalisis jenis sekolah yang ada untuk memberikan gambaran aktual tentang nilai yang ditawarkan sekolah tersebut. Contoh, pada tabel 2 menunjukkan analisis untuk menemukan faktor diferensiasi Sekolah Pelita Harapan. Berdasarkan analisis, Sekolah Pelita Harapan memiliki delapan indikator yang masuk dalam kategori segmen A. Konsekuensinya adalah mahalnya harga, bahkan di antara sekolah internasional di Indonesia. 
Volume : 7

Nomor : 2

Bulan : Mei

Tahun : 2021 URL: jurnal.ideaspublishing.co.id

Tabel 2

Diferensiasi untuk Sekolah Pelita Harapan Indonesia

\begin{tabular}{llll}
\hline \multicolumn{1}{c}{ Nilai Diferensiasi } & \multicolumn{1}{c}{ A } & \multicolumn{1}{c}{ B } & Cublik \\
\hline Kepemilikan & Swasta nasional $\checkmark$ & Swasta lokal & Pemerintah \\
\hline Afiliasi & $\begin{array}{l}\text { Yayasan yang didirikan oleh } \\
\text { perusahaan } \checkmark\end{array}$ & Yayasan mandiri & \\
\hline Bahasa yang digunakan & Bahasa asing $\checkmark$ & Bahasa Inggris & Indonesia \\
\hline Latar belakang budaya & Multikultural $\checkmark$ & Spesifik negara tertentu & Indonesia \\
\hline Kurikulum & Internasional $\checkmark$ & $\begin{array}{l}\text { Spesifik salah satu jenis } \\
\text { kurikulum }\end{array}$ & Publik \\
\hline Waktu belajar di sekolah & Sekolah berasrama $\checkmark$ & Full day school & Sekolah \\
& Berdasarkan nilai-nilai agama & Berdasarkan nilai-nilai & Publik \\
Nilai etika & tertentu $\checkmark$ & $\begin{array}{l}\text { tertentu yang tidak selalu } \\
\text { berdasar nilai agama }\end{array}$ & \\
\hline Jalur ke perguruan tinggi & Multijalur $\checkmark$ & Jalur yang spesifik & Umum \\
\hline Fasilitas & Lengkap $\checkmark$ & Tersedia & Dasar \\
\hline Harga & Tinggi $\checkmark$ & Tinggi ke medium & Hampir gratis \\
\hline
\end{tabular}

Sumber: Berbagai Sumber, Penulis, 2020.

Selanjutnyak diferensiasi dilakukan di sekolah lain untuk mengetahui siapa segmennya. Contoh kedua pada tabel ketiga adalah Sekolah Lab School, sebuah sekolah swasta ternama di Indonesia. Perbedaan terlihat jelas, yaitu Lab School merupakan sekolah menengah dengan perbedaan faktor yang terletak pada segmen B dan C. Di Sekolah Pelita Harapan, faktor yang paling membedakan ada di segmen A. Hal tersebut menyebabkan Sekolah Pelita Harapan memiliki biaya pendidikan yang tinggi dan melayani segmen atas.

Sebagai perbandingan, Lab School berada di segmen B untuk segmen menengah dan atas. Kedua sekolah ini hanyalah contoh. Tabel faktor diferensiasi ini berguna untuk membedakan berbagai sekolah di Indonesia guna mengidentifikasi nilai yang dijual dan menampilkan lokasi sekolah.

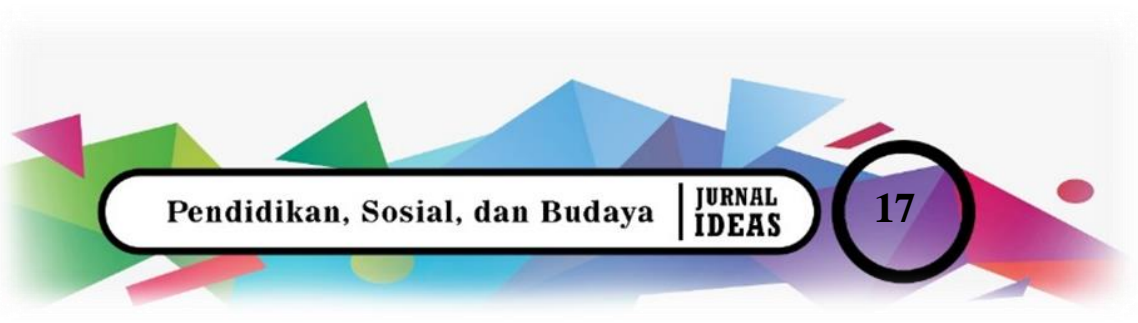


TE E-ISSH: 2656-940X

(1) P-ISSH: 2442-36TK

URL: jurnal.ideaspublishing.co.id
Volume : 7

Nomor : 2

Bulan : Mei

Tahun : 2021

Tabel 3

Diferensiasi yang Digunakan oleh Sekolah Lab School Indonesia

\begin{tabular}{|c|c|c|c|}
\hline Nilai Diferensiasi & $\mathbf{A}$ & B & $\mathbf{C}$ \\
\hline Kepemilikan & Swasta nasional $\checkmark$ & Swasta lokal & Publik \\
\hline Afiliasi & $\begin{array}{l}\text { Yayasan yang didirikan oleh } \\
\text { perusahaan. }\end{array}$ & Yayasan mandiri $\checkmark$ & Pemerintah \\
\hline Bahasa yang digunakan & Bahasa asing & Bahasa Inggris & Indonesia $\checkmark$ \\
\hline Latar belakang budaya & Multikultural & Spesifik negara tertentu & Indonesia $\checkmark$ \\
\hline Kurikulum & Internasional & $\begin{array}{l}\text { Spesifik salah satu jenis } \\
\text { kurikulum } \checkmark\end{array}$ & Publik \\
\hline Waktu belajar di sekolah & Sekolah berasrama & Full day school $\checkmark$ & $\begin{array}{l}\text { Sekolah pulang } \\
\text { hari }\end{array}$ \\
\hline Nilai etika & $\begin{array}{l}\text { Berdasarkan nilai-nilai agama } \\
\text { tertentu } \checkmark\end{array}$ & \begin{tabular}{lr}
\multicolumn{2}{l}{ Berdasarkan nilai-nilai } \\
tertentu yang tidak \\
selalu berdasar nilai \\
agama
\end{tabular} & Publik \\
\hline Jalur ke perguruan tinggi & Multijalur & Jalur yang spesifik & Umum $\checkmark$ \\
\hline Fasilitas & Lengkap & Tersedia $\checkmark$ & Dasar \\
\hline Harga & Tinggi & Tinggi ke medium $\checkmark$ & Hampir gratis \\
\hline
\end{tabular}

Sumber: Berbagai Sumber, Penulis, 2020

Kriteria diferensiasi cenderung menjadi satu bagian sehingga dapat menentukan segmen sekolah. Hal ini juga disadari oleh pemerintah dengan membuat sekolah bertaraf internasional. Tindakan ini sebagai bentuk respons pemerintah terhadap kemajuan zaman di era globalisasi yang membutuhkan sumber daya yang berkualitas termasuk di dalamnya memiliki kemampuan berbahasa asing yang baik. Menariknya, dengan dimulainya sekolah internasional, penggunaan bahasa asing lebih intensif meningkat.

Konsekuensi dari sekolah negeri bergelar percontohan berstandar internasional ini lebih tinggi atau relatif mahal dibanding sekolah negeri sekitarnya. Pemerintah menyadari nilai penggunaan bahasa Inggris yang diapresiasi oleh masyarakat untuk menciptakan biaya sekolah bertaraf internasional dengan biaya pendidikan yang lebih tinggi (Saputra, 2020).

\section{Pembahasan}

Berdasarkan hasil penelitian yang telah dilakukan, maka berikut ini akan dibahas temuan sepuluh faktor diferensiasi sekolah di Indonesia. Faktor diferensiasi pertama adalah kepemilikan sekolah. Kepemilikan sekolah memberikan konsekuensi yang berbeda bagi siswa. Misalnya sekolah yang dimiliki oleh pemerintah atau biasa 
Volume : 7

Nomor : 2

Bulan : Mei

Tahun : 2021

disebut sekolah negeri, harganya murah atau hampir gratis karena adanya subsidi negara. Harga yang murah bahkan hampir gratis menampilkan sekolah negeri yang umumnya memiliki lebih sedikit fasilitas dan lebih banyak siswa per kelas. Berbeda dengan sekolah swasta yang biasanya memiliki fasilitas lebih banyak sesuai dengan harga yang dibayarkan.

Faktor diferensiasi kedua adalah afiliasi sekolah. Afiliasi sekolah yang dimaksud adalah sekolah yang didirikan dengan latar belakang perusahaan seperti sekolah di bawah naungan Yayasan Pelita Harapan.

Yayasan Pelita Harapan memiliki tiga harga sekolah untuk tiga elemen. elemen termahal yaitu sekolah dengan kurikulum international baccalaureate yang diberi nama Sekolah Harapan Penerangan. Sekolah ini berbasis kawasan pemukiman mewah yang bisa ditemukan di mal milik Grup Lippo. Elemen kedua adalah elemen kelas menengah dengan kurikulum nasional yang memiliki fasilitas yang baik, tetapi tidak semewah Sekolah Harapan Penerangan. Sekolah ini bernama sekolah Dian Harapan. Ketiga adalah sekolah murah dengan berbagai beasiswa yang terletak di daerah dengan perekonomian lemah yang diberi nama Sekolah Lentera Harapan.

Nama yayasan yang berlatar belakang perusahaan memiliki arti yang menjual, seperti Yayasan Pelita Harapan, Yayasan Pendidikan Ciputra, Yayasan Pendidikan Universitas Presiden. Yayasan-yayasan tersebut adalah beberapa yayasan yang dimiliki oleh perusahaan properti. Perusahaan mendirikan lembaga pendidikan di atas properti yang dibangun. Secara regulasi, pemerintah mengisyaratkan suatu daerah perlu memiliki lingkungan pendidikan dimulai dari PAUD sampai dengan perguruan tinggi agar dapat dianggap sebagai daerah mandiri atau kota satelit.

Sekolah tanpa afiliasi di luar perusahaan dapat berafiliasi dengan lembaga sosial, agama tertentu, atau yayasan nonafiliasi. Sekolah dengan afiliasi keagamaan umumnya menerapkan subsidi silang. Contoh, sekolah Katolik di kota besar menyumbangkan sebagian pendapatannya ke sekolah Katolik yang terletak di kota kecil atau daerah terpencil (Sepich, 2020).

Diferensiasi ketiga adalah penggunaan bahasa asing. Penggunaan bahasa asing ini bukan hanya bahasa Inggris. Saat ini, umumnya di sekolah menggunakan bahasa Inggris sebagai bahasa asing. Hal ini dapat dimaklumi karena bahasa Inggris 


\begin{tabular}{|c|c|}
\hline 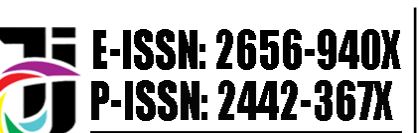 & $\begin{array}{l}\text { Volume : } 7 \\
\text { Nomor : } 2 \\
\text { Rulan }\end{array}$ \\
\hline URL: jurnal.ideaspublishing.co.id & Tahun : 2021 \\
\hline
\end{tabular}

merupakan lingua franca yang digunakan oleh kebanyakan orang di dunia (Agustin, 2015). Bahasa asing lainnya yang digunakan adalah bahasa Mandarin. Beberapa orang menganggap bahasa Mandarin sebagai bahasa yang dibutuhkan dalam dunia bisnis. Selain kedua bahasa tersebut, ada juga bahasa Perancis dan Jepang. Kedua bahasa ini digunakan sekolah yang berafiliasi dengan kedua negara tersebut. Selain itu, terdapat pula bahasa Arab yang digunakan oleh sekolah yang berlatar belakang agama Islam (Muradi, 2019).

Sementara itu, sekolah negeri menggunakan bahasa Indonesia, tetapi tetap menjadikan bahasa Inggris sebagai bagian dari kurikulum wajib dan ada bahasa asing lainnya sebagai bagian dari ekstrakurikuler. Bahasa asing apa pun adalah nilai yang membedakan dan sebagai pendorong nilai dilihat dari biaya sekolah yang lebih tinggi. Hal ini juga terkait dengan tumbuhnya persepsi orang tua siswa di Indonesia tentang pentingnya menguasai bahasa asing. Oleh karena itu, dengan adanya kebutuhan tersebut, ada sekolah yang memberikan nilai berupa bahasa asing sebagai nilai jual utama atau tambahan bagi penciri kualitas sekolahnya.

Diferensiasi keempat adalah latar belakang budaya. Ide dari diferensiasi ini adalah bahwa harapan orang tua terhadap kemampuan anaknya tidak hanya kemampuan berbahasa saja, tetapi peserta didik juga memiliki perilaku yang tercermin dalam penggunaan bahasa tersebut. Jadi, seorang siswa tidak hanya dapat berbicara bahasa Inggris, tetapi juga mencerminkan pendidikan barat. Begitu pula dengan bahasa Jepang yang berlatar belakang budaya Jepang, sehingga menjadikan siswa memiliki kedisiplinan khas bangsa Jepang. Sekolah dengan bahasa Mandarin juga mengenalkan siswa pada budaya Mandarin. Harapan ke depannya, ketika siswa melanjutkan pendidikan di Cina, sudah terbiasa dengan budaya lokal dan tidak ada gegar budaya (Mat, 2010). Begitu juga dengan sekolah yang memasukkan pembelajaran bahasa Arab. Kememapuan berbahasa Arab seorang siswa menjadi bekal yang memudahkan bagi mereka yang nantinya ingin melanjutkan studi di negara seperti Mesir.

Diferensiasi kelima adalah kurikulum. Di Indonesia, untuk lulus dari sistem pendidikan Indonesia, siswa harus mengikuti kurikulum Indonesia atau lulus menggunakan ujian persamaan yang di Indonesia disebut dengan ujian paket 
Volume : 7

Nomor : 2

Bulan : Mei

Tahun : 2021

(Nurahdawati dkk., 2020). Untuk beberapa profesi, idealnya siswa menempuh jenjang S-1 di Indonesia, terutama untuk jurusan seperti kedokteran, farmasi, dan hukum. Namun, di satu sisi, para orang tua tetap menginginkan anaknya mengenyam pendidikan dasar dan menengah dengan gaya internasional. Oleh karena itu, beberapa sekolah internasional juga memfasilitasi hal tersebut.

Sekolah di Indonesia yang menggunakan bahasa Inggris sebagai bahasa pengantar terbagi menjadi dua, yaitu sekolah dengan kurikulum internasional, seperti kurikulum international baccalaureate atau kurikulum Cambridge dan kurikulum nasional yang menggunakan bahasa Inggris sebagai bahasa pengantar. Sekolah yang menggunakan kurikulum internasional umumnya memiliki biaya pendidikan yang lebih tinggi. Hal ini disebabkan dengan menggunakan kurikulum tersebut memiliki konsekuensi yaitu ada biaya yang harus dibayarkan kepada penyelenggara kurikulum berupa biaya langganan tahunan (Saputro, 2013).

Selain kurikulum internasional, beberapa sekolah memiliki kurikulum khusus negara, seperti Singapura, Jepang, atau Australia. Penggunaan kurikulum internasional ini akan bermanfaat ketika mahasiswa menempuh kuliah di luar negeri, terutama karena untuk masuk ke berbagai perguruan tinggi di luar negeri terdapat persyaratan berupa pelajaran khusus yang harus diambil mahasiswa. Siswa yang lulus dari sekolah tersebut dapat langsung masuk ke jenjang universitas tanpa melalui jenjang yayasan. Penghematan waktu merupakan keuntungan yang nyata (Rindawan, 2019).

Diferensiasi keenam adalah studi komprehensif di sekolah. Di Indonesia ada istilah full day school, yaitu sekolah hingga sore. Siswa belajar di sekolah selama lebih dari delapan jam sehari. Namun, sekolah ini tidak akan beroperasi pada hari Sabtu sehingga waktu belajar tetap sekitar 40 jam dalam seminggu (Hasan, 2006). Sekolah fullday school umumnya berada di perkotaan. Oleh karena itu, mereka menggunakan siklus hari kerja di perkotaan, yaitu lima hari kerja. Sekolah negeri umumnya diselenggarakan enam hari. Meskipun begitu, sistem sekolah negeri menerapkan sistem pembelajaran sehari. Siswa belajar selama 40 jam dari Senin hingga Jumat dan Sabtu dikhususkan untuk ekstrakurikuler.

Untuk sekolah berasrama, seperti pesantren, terbagi menjadi dua sekolah. Pertama, yang dirancang dengan sistem sekolah berasrama atau full day. Sekolah ini 


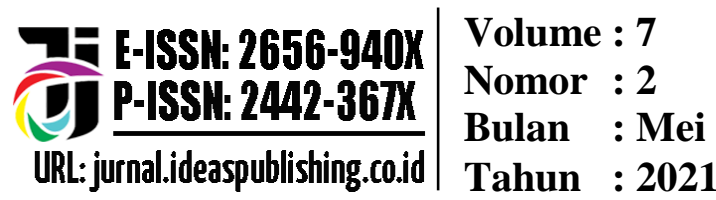

bertujuan bagi anak-anak dari daerah terpencil. Namun, tidak menutup kemungkinan sekolah yang hendak menerapkan sistem asrama juga menerima anak-anak dari lingkungan seputar sekolah dan siswanya tetap harus tinggal di asrama meski berdomisili di tempat yang sama dengan sekolah. Tujuannya yaitu untuk membangun budaya kemandirian (Lobian, 2019). Beberapa pesantren memiliki sistem semimiliter dengan tujuan membentuk karakter disiplin. Pesantren juga termasuk menggunakan bahasa tertentu, seperti pesantren yang mengharuskan menggunakan bahasa asing.

Diferensiasi ketujuh adalah nilai-nilai etika yang digunakan sekolah. Nilai moral ini bersumber dari agama tertentu yang menjadi warna sekolah, seperti sekolah dengan latar belakang agama yang diakui di Indonesia. Nilai moral lainnya bisa berasal dari etika kebangsaan. Di sekolah negeri, pembagian kurikulum merupakan kurikulum wajib dari pusat yang berlaku untuk semua sekolah negeri di Indonesia dan muatan lokal. Nilai budaya lokal ditambahkan ke dalam kurikulum muatan lokal (Syaifuddin \& Fahyuni, 2019).

Diferensiasi kedelapan adalah jalur yang ada di sekolah. Terdapat kurikulum kelas atau ekstrakurikuler di sekolah swasta internasional yang dirancang secara eksplisit untuk mempersiapkan peserta didik ke jenjang berikutnya. Contohnya, jalur yang terdiri dari beberapa profesi, seperti kedokteran, bisnis, seni, atau desain. Sekolah memfasilitasi ini dengan memberikan pelajaran yang menjadi dasar dari disiplin yang dipilih. Cara lain adalah menjembatani peserta didik untuk magang mengikuti karir yang akan mereka praktikkan di masa depan (Chavez, 2019). Selain sekolah multijalur tersebut, terdapat juga sekolah yang memiliki nilai khusus, seperti menciptakan jiwa kewirausahaan atau menyatukan peserta didik dengan alam. Sementara itu, di sekolah negeri, seorang peserta didik tidak dipersiapkan untuk memiliki jalur tertentu, tetapi hanya secara umum. Di sekolah umum ada pembagian jalur menjadi tiga, yaitu bidang kekhususan bahasa, sains, dan ilmu sosial.

Diferensiasi kesembilan adalah fasilitas yang disediakan. Di sekolah swasta dengan segmen kelas atas, fasilitas yang diberikan juga luar biasa. Ada fasilitas kolam renang standar Olimpiade atau lapangan sepak bola resmi federasi sepak bola FIFA. Fasilitas tersebut semacam keuntungan yang diberikan karena sekolah ini tidak bertujuan untuk mencetak atlet. Di sekolah dengan fasilitas segmen tinggi dan 
Volume : 7

Nomor : 2

Bulan : Mei

Tahun : 2021

menengah yang tersedia lengkap tanpa menggunakan standar yang sama, seperti di sekolah dengan biaya pendidikan tinggi. Berbeda dengan sekolah umum, fasilitas di sekolah umum bergantung pada jenis sekolah. Untuk sekolah negeri yang tergolong sekolah favorit, fasilitas yang diberikan juga akan lebih baik. Sekolah umum bukan favorit akan memiliki fasilitas yang lebih sedikit.

Diferensiasi kesepuluh adalah harga. Harga merupakan konsekuensi dari diferensiasi dan nilai yang diberikan oleh sebuah sekolah. Sekolah yang menawarkan lebih banyak bobot dapat meminta biaya sekolah yang lebih tinggi. Berbeda dengan sekolah negeri yang dibiayai oleh negara. Jika nilainya saat ini tidak dapat diterima oleh masyarakat, maka sekolah tersebut akan memiliki siswa yang lebih sedikit dan selanjutnya ditutup karena kekurangan siswa. Misalnya, di sekolah internasional dengan latar belakang agama tertentu dan menggunakan bahasa Inggris, serta sekolah berasrama akan lebih mahal dibandingkan sekolah dengan pengalaman spiritual atau sekadar menjual penggunaan bahasa Inggris tanpa menggunakan kurikulum internasional secara resmi.

\section{Simpulan}

Penelitian menemukan sepuluh faktor diferensiasi sekolah di Indonesia, yaitu yaitu afiliasi, bahasa yang digunakan, latar belakang budaya, kurikulum, waktu belajar di sekolah, nilai etika, jalur ke perguruan tinggi, fasilitas, dan harga. Sepuluh faktor diferensiasi ini diperoleh dari tiga segmen sekolah Indonesia.

\section{Daftar Rujukan}

Agustin, Y. (2015). "Kedudukan Bahasa Inggris sebagai Bahasa Pengantar dalam Dunia Pendidikan". Deiksis, 3(04), 354-364.

Hasan, N. (2006). "Full Day School (Model Alternatif Pembelajaran Bahasa Asing)". Tadris: Jurnal Pendidikan Islam, 1(1).

Idris, R. (2010). "APBN Pendidikan dan Mahalnya Biaya Pendidikan". Lentera Pendidikan: Jurnal Ilmu Tarbiyah dan Keguruan, 13(1), 92-110.

Kornbluh, M. (2019). "Untold Student Stories: Examining Educational Budget Cuts within Urban School Settings". Journal of Urban Affairs, 1-19.

Lobian, S. (2019). "Metode Pembelajaran Kooperatif Stad untuk Meningkatkan Kemampuan Klasifikasi dan Sosial Emosional Siswa di TK Sekolah Pelita Harapan Pluit Village Jakarta". Doctoral Dissertation, Universtas Pelita Harapan.

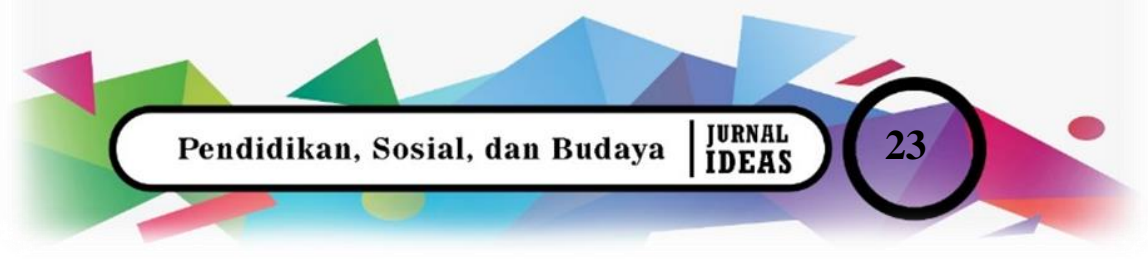


Mat, A. C. (2010). "Situasi Pembelajaran Bahasa Asing di Institut Pengajian Tinggi: Perbandingan antara Bahasa Arab, Bahasa Mandarin, dan Bahasa Perancis”. Asean Journal of Teaching and Learning in Higher Education (AJTLHE), 2(2), 920.

Muradi, A. (2019). "Tujuan Pembelajaran Bahasa Asing (Arab) di Indonesia”. Jurnal Al Maqayis, 1(1).

Nurahdawati, N.; Ruliana, R.; \& Ahmar, A. S. (2020). "Model Spasial Autoregresif (SAR) Durbin pada Anak Putus Sekolah (APS) yang Mengikuti Ujian Paket C Jenjang SMA Sederajat di Kota Makassar”. VARIANSI: Journal of Statistics and Its application on Teaching and Research, 2(2).

Rindawan, I. K.; \& Asih, N. L. P. S. (2019, October). "Implementasi Pembelajaran Pendidikan Pancasila dan Kewarganegaraan di Sekolah Dasar Australian Independent School Kerobokan, Kecamatan Kuta Utara, Kabupaten Badung". In Seminar Nasional Hukum dan Kewarganegaraan, 1(1), 94-99.

Saputra, Y. (2020). "Analisis Putusan Mahkamah Konstitusi Nomor 5/PUU-X/2012 dalam Kaitannya dengan Kualitas Sekolah Eks RSBI”. JUSTISI, 6(1), 46-51.

Saputro, S. (2013). "Manajemen Kurikulum Sekolah Standar Internasional berbasis Integrasi Standar Nasional dan Cambridge International Primary Programme". Disertasi. Disertasi dan Tesis Program Pascasarjana UM.

Syaifuddin, M. A., \& Fahyuni, E. F. (2019). "Penguatan Pendidikan Karakter melalui Kurikulum Muatan Lokal di SMP Muhammadiyah 2 Taman”. PALAPA, 7(2), 267-285.

Togatorop, M. (2017). "Pengaruh Biaya Pendidikan Terhadap Mutu Sekolah SMA Swasta”. SCHOLARIA: Jurnal Pendidikan dan Kebudayaan, 7(3), 234-240. 